\title{
Tangence
}

\section{Genèse interculturelle de la littérature africaine. Mises en perspectives et conséquences pour l'enseignement}

\section{Hans-Jürgen Lüsebrink}

Numéro 49, décembre 1995

Les littératures francophones de l’Afrique et des Antilles

URI : https://id.erudit.org/iderudit/025876ar

DOI : https://doi.org/10.7202/025876ar

Aller au sommaire du numéro

Éditeur(s)

Tangence

ISSN

0226-9554 (imprimé)

1710-0305 (numérique)

Découvrir la revue

Citer cet article

Lüsebrink, H.-J. (1995). Genèse interculturelle de la littérature africaine. Mises en perspectives et conséquences pour l'enseignement. Tangence, (49), 32-48.

https://doi.org/10.7202/025876ar d'utilisation que vous pouvez consulter en ligne. 


\section{Genèse interculturelle de la littérature africaine. Mises en perspectives et conséquences pour l'enseignement}

\section{Hans-Jürgen Lüsebrink}

\section{Mises en perspectives : le double héritage des littératures africaines}

Les littératures francophones sont issues de l'histoire de l'expansion coloniale de la France d'outre-mer, entre le début du $\mathrm{Xv}^{\mathrm{e}}$ et les premières décennies $\mathrm{du} \mathrm{xx}^{\mathrm{e}}$ siècle. Se déroulant en deux phases bien distinctes, entre 1534 et 1763 d'abord, et ensuite entre 1830 et 1962, l'expansion coloniale française a eu pour conséquence, sur le plan culturel, la genèse de situations de plurilinguisme et parfois de colinguisme ${ }^{1}$ sous des formes très variées. Celles-ci vont de la coexistence, souvent conflictuelle et marquée par une forte volonté d'acculturation coloniale, de langues et cultures essentiellement orales, en Afrique noire, à la confrontation entre deux cultures écrites, au Maghreb, jusqu'à l'émergence de littératures et cultures créolophones dans les Caraïbes et dans l'océan Indien. S'y ajoutent des constellations particulières, où le français s'est trouvé minorisé, suite aux aléas de l'histoire coloniale, par l'anglais, comme langue administrative, scolaire et littéraire, comme cela a été le cas au Québec, dans les provinces maritimes du Canada ainsi qu'à l'île Maurice et en Louisiane.

Cette mise en relief historique situe les littératures africaines, francophones dans une double perspective, à la fois diachronique et synchronique, dans lesquelles elles se trouvent ancrées, depuis leur genèse dans les années vingt $\mathrm{du} \mathrm{xx}^{\mathrm{e}}$ siècle:

- La perspective syncbronique distinguera deux traits de caractères fondamentaux de toutes les littératures africai-

1 Voir sur ce terme Étienne Balibar (Le colinguisme, Paris, P.U.F., 1993, p. 4) qui désigne par ce terme "l'association de certaines langues écrites (le colinguisme), ou en particulier certaines associations historiques de langues écrites. " Voir sur les constellations de langues dans le monde francophone aussi Louis-Jean Calvet, La guerre des langues et les politiques linguistiques, Paris, Payot, 1987. 
nes, et plus largement de toutes les littératures issues d'un contexte colonial, à savoir, d'une part, leur ancrage dans la culture coloniale, ses modèles de pensée et d'écriture, son idéologie, sa conception de la civilisation et du progrès. Eileen Julien a mis en cause à ce sujet, dans son livre The African Novel and the Question of Orality, notamment l'influence, prétendument prépondérante, de grands auteurs européens sur les écrivains africains, tout en soulignant leur enracinement dans les littératures et cultures orales, leurs genres, leurs formes de communication et leurs mentalités ${ }^{2}$. Cette synchronie à double face traverse les littératures africaines, francophones et anglophones, dès leurs débuts dans les années vingt du $\mathrm{xx}^{\mathrm{e}}$ siècle, avec une intensité inégale, mais permanente. Et elle se trouve présente, dans une co-présence parfois contradictoire et violente, dans de très nombreux ouvrages des littératures africaines écrites. Deux exemples qui paraissent significatifs pour cette double mise en perspective seront évoqués au cours de cette contribution :

- un poème de Léopold Sédar Senghor, tiré de son recueil Hosties noires;

- et le roman Le devoir de violence de Yambo Ouologuem, écrivain malien.

- La perspective diachronique, c'est-à-dire le questionnement de la dimension historique dans laquelle s'ancrent les littératures africaines écrites, sera fondée sur une distinction socioculturelle des grandes étapes de l'évolution des littératures africaines francophones, depuis leur origine jusqu'à nos jours. On peut essentiellement relever trois étapes différentes qui seront traitées successivement par la suite ${ }^{3}$ :

2 Eileen Julien, African Novels and the Question of Orality, Bloomington and Indianapolis, Indiana University Press, 1992; voir aussi dans la même perspective les travaux de Werner Glinga, Literatur in Senegal. Geschicbte, Mythos und gesellschaftliches Ideal in der oralen und scbriftichen Literatur, Berlin, Reimer, 1990; Amadou Koné, "Des textes oraux au roman moderne. Étude sur les avatars de la tradition orale dans le roman ouest-africain ", Frankfurt/M., Verlag für Interkulturelle Kommunikation, 1993 (Studien zu den frankopbonen Literaturen außerbalb Europas vol. 2).

3 Ce tableau historique suivra dans l'ensemble les grandes lignes du chapitre "Die frankophonen Literaturen Schwarzafrikas" que nous [H.-J. L.] avons rédigé pour une histoire des littératures française et francophones en Allemagne 
34

I. Le contexte de formation, 1920-1945;

II. Les littératures de la résistance anticoloniale, 1945-1960;

III. Les littératures africaines dans le contexte des indépendances, depuis 1960.

\section{Étapes et paradigmes}

\section{Le contexte de formation (1920-1945)}

Les littératures francophones africaines sont apparues dans les années vingt de ce siècle sur un continent où dominaient, jusqu'à la conquête par les puissances coloniales européennes, des formes de communication, de culture et de littérature essentiellement orales. C'est uniquement dans les régions du Sahel, fortement marquées par l'Islam, qu'on peut trouver les traces d'une culture écrite antérieure au colonialisme, d'une "littérature" centrée autour des villes de Tombouctou (Mali) et de Touba (Sénégal). À partir des comptoirs commerciaux fondés au début du XVII $^{\mathrm{e}}$ siècle sur les côtes de la Guinée et du Sénégal, va commencer à se développer, au milieu du $\mathrm{xrx}^{\mathrm{e}}$ siècle, l'expansion coloniale française vers le centre de l'Afrique: une expansion qui va non seulement transformer profondément la carte politique du continent africain, mais également les conditions fondamentales de la production culturelle et littéraire. En 1848 est installée sur lîle de Gorée près de la côte du Sénégal, la première presse d'imprimerie des colonies françaises d'Afrique noire, sur laquelle sera imprimé le premier journal en langue française du continent africain, le Bulletin du Sénégal. Depuis les années quatre-vingtdix du $\mathrm{xIx}^{\mathrm{e}}$ siècle, l'attribution de droits civiques et du droit de vote à une étroite couche d'Africains, les "évolués", pour la plupart employés dans l'administration coloniale, s'est accompagnée de l'apparition d'une presse politique se détachant progressivement des positions des organes de presse officiels. Cette nouvelle presse politique deviendra bientôt le médium d'une prise de conscience politique autonome, tout d'abord au Sénégal, à partir des années vingt de ce siècle également dans d'autres colonies françaises comme le Dahomey, la Côte d'Ivoire et le Cameroun, puis enfin, dans les années quarante, la colonie belge du Congo.

éditée par Jürgen Grimm, Französische Literaturgeschicbte. 3., um die frankopbonen Literaturen außerbalb Frankreichs erweiterte Ausgabe, Stuttgart/ Weimar, Metzler, 1994, p. 425-438. 
Le développement de l'enseignement primaire depuis le début du $\mathrm{xx}^{\mathrm{e}}$ siècle et celui de l'enseignement secondaire à partir des années vingt, avait pour but premier de former des enseignants et des fonctionnaires de l'administration parmi la population indigène; mais cette évolution a favorisé en même temps la naissance d'une presse littéraire et culturelle ouvrant déjà ses colonnes, entre les deux guerres mondiales, à quelques auteurs africains. Le Bulletin de l'enseignement de l'Afrique occidentale française, publié à Dakar depuis 1913, joua ici un rôle essentiel. Conçu à l'origine comme une revue pédagogique, il servit à de nombreux auteurs africains de la première génération de forum de publication pour des études ethnographiques, mais également pour des poèmes et des contes issus pour la plupart de la tradition orale. La Reune africaine de littérature, fondée en 1926 et dont l'existence a été de courte durée, ainsi que les pages littéraires et culturelles insérées depuis les années vingt dans des journaux comme Le phare du Dabomey et Paris-Dakar, constituent enfin le noyau à partir duquel allait se construire un espace public littéraire et culturel en Afrique noire francophone ${ }^{4}$.

La politique culturelle coloniale encourageait donc ainsi, avec des objectifs ouvertement idéologiques, la naissance d'une littérature africaine en langue française. Afin d'étudier systématiquement les modes de pensée et les comportements de leurs écoliers, les responsables politiques offrirent à des instituteurs africains, tels les - futurs - écrivains Amadou Mapaté Diagne, Paul Hazoumé et Fily Dabo Sissoko, la possibilité de publier dans le très officiel Bulletin de l'Enseignement de l'A.O.F. des proverbes populaires et des textes ethnographiques. Des "enquêtes" et des "concours", organisés périodiquement, vinrent en outre à l'appui de cette forme de "prise de parole" ethnographique et littéraire des auteurs africains. Il en est ainsi de l'"Enquête sur l'Enfant Noir", organisée en 1930 par le Bulletin de l'enseignement de l'A.O.F., ou encore du concours littéraire sur le théâtre et celui sur la littérature narrative, organisés respectivement en 1948

4 Voir sur ce point Denise Bouche, "Autrefois, notre pays s'appelait la Gaule..." Remarques sur l'adaptation de l'enseignement au Sénégal de 1817 à 1960", Cabiers d'études africaines, vol. VIII, $n^{\circ} 29,1968$, p. 110-122; HansJürgen Lüsebrink, Scbrift, Bucb und Lektïre in der französiscbspracbigen Literatur Afrikas. Zur Wabrnebmung und Funktion von Scbriftlicbkeit und Bucblektüre in einem kulturellen Epocbenumbruch der Neuzeit, Tübingen, Niemeyer, 1990. 
et en 1951 dans la revue La voix du Congolais, le premier périodique culturel et littéraire du Congo belge ${ }^{5}$. La multitude des réponses reçues et pour la plupart publiées, marque les débuts de la littérature francophone dans la partie belge de l'Afrique centrale. Même la genèse du théâtre francophone africain est à mettre au compte d'une volonté de la politique coloniale. Celui-ci est en effet né en 1933 à l'école William Ponty, une école supérieure de formation des enseignants à Gorée près de Dakar, à l'initiative de son directeur Charles Béart. En incitant ses meilleurs élèves, tel le futur écrivain et ministre de l'éducation de la Côte d'Ivoire Bernard Binlin Dadié, à écrire et mettre en scène des pièces de théâtre, Charles Béart poursuivait, conformément à la doctrine assimilationniste de la Troisième République en matière coloniale, un double objectif: il désirait d'une part motiver les étudiants, en tant qu'élite de la population africaine, à manier la langue française de façon créative, ce qui pouvait déboucher, selon Béart, sur la formation d'une littérature africaine. D'autre part, les thèmes et les contenus choisis devaient être, si possible, tirés des traditions narratives orales des différentes cultures ethniques, ce qui permettrait d'éviter une rupture entre les traditions orales et écrites et de renforcer la prise de conscience de la continuité et de la complémentarité existant entre ces deux formes de culture, tout en développant la capacité de traduire d'une forme dans l'autre. Les représentations théâtrales de l'école William Ponty ont eu lieu publiquement et avec un grand succès à Dakar depuis 1934, et faisaient l'objet de larges comptes rendus dans la presse africaine. La présentation des tragédies d'auteur collectif Sokamé (1937) et Les prétendants rivaux (1937 à l'occasion de l'Exposition universelle de Paris) fit découvrir pour la première fois au public français l'existence d'un théâtre africain francophone.

5 Voir sur ce point Hans-Jürgen Lüsebrink : "Le Congo Belge s'ouvre à la littérature". Impact et contexte historique des concours littéraires de La voix $d u$ Congolais en 1940-1951", dans Pierre Halen/ János Riesz (dir.), Littératures du Congo-Zaïre. Actes du colloque international de Bayreuth (22-24 juillet 1993), Amsterdam, Rodopi, 1995, p. 197-207 ( $\mathrm{n}^{\text {os }} 13 / 14$ de la revue Matatu). 


\section{Les littératures de la résistance anticoloniale (1945-1960)}

La défaite française de 1940, la Résistance et la Seconde Guerre mondiale dans son ensemble, transformèrent fondamentalement les formes d'expression de la littérature et la structure de l'espace public littéraire dans les colonies françaises et belges d'Afrique. La séparation vécue d'avec la mère-patrie allait donner naissance, dans les colonies d'outre-mer, à une nouvelle prise de conscience politique, qui s'exprima à travers de nombreux mouvements de révolte: en Algérie (Constantine 1945), à Madagascar (1947), au Sénégal (Thiaroye 1945), et dans les deux guerres coloniales, celle d'Indochine (1946-1954) et d'Algérie (1954-1962). La dynamique de ces mouvements se trouva ancrée dans la revendication des peuples coloniaux de bénéficier des principes fondamentaux d'égalité des droits et d'autonomie ancrés dans le préambule de la constitution de la rve République, et avec lesquels la politique coloniale française se trouve en contradiction radicale.

Dans la presse, publiée tant en France qu'en Afrique de l'Ouest et en Afrique centrale, ainsi que dans les cuuvres des écrivains africains, ce processus de prise de conscience politique laisse des traces profondes. Chez des auteurs comme Léopold Sédar Senghor, Bernard Dadié, Fodéba Keïta, Fily Dabo Sissoko, Camara Laye et Birago Diop, cette politisation croissante s'exprima à travers une mise en valeur ostentatoire de la propre culture, caractérisée essentiellement par des formes narratives orales et chantées; elle se traduit également, à partir du début des années cinquante, par le développement rapide d'une littérature anticoloniale militante, dont témoignent avant tout les cuvres de Ferdinand Oyono, d'Ousmane Sembène et de Mongo Beti. Bernard Dadié, condamné en 1949-1950 à une peine d'un an de prison pour "activités antifrançaises", a formulé de façon programmatique dans son plaidoyer devant le tribunal de Grand-Bassam - qu'il publie plus tard sous le titre Carnet de prison (1981) cette revendication d'une égalité dans le domaine culturel, qui sous-tendît l'exigence d'une séparation politique d'avec la France:

Monsieur le Président, Messieurs de la Cour, les Contes de Perrault nous enchantent, mais les ruses du lièvre et de l'araignée nous enthousiasment. C'est pourquoi nous voulons venir à l'Union française avec notre fond proposé. Nous entendons, après avoir parlé de Vercingétorix, parler de tous nos Amadou 
38

Bamba, qui se font sauter dans leurs forteresses assiégées. Nous voulons, après avoir parlé de Jeanne d'Arc, parler de toutes nos héroïnes, de toutes nos amazones, de cette reine Aoura Pokou qui, pour la liberté de son peuple, jette dans le Bandama son unique enfant. [...] Mais partout, nous ne rencontrons que des obstacles, des entraves. L'on semble vouloir étouffer notre génie afin de mieux nous asservir. ${ }^{6}$

Le genre littéraire le plus important dans les années 19451960 était, avec le roman, sans conteste la poésie. 1947 fut l'année de fondation, avec l'appui, entre autres, de J.-P. Sartre et A. Gide, de la revue Prêsence africaine, qui réserva dès ses débuts une large place, à côté de la critique littéraire et des essais, à la poésie ${ }^{7}$. C'est en 1948 que parut à Paris, avec une préface de J.-P. Sartre, l'Anthologie de la nouvelle poésie noire et malgache de langue française, éditée par Senghor et dans laquelle la poésie africaine se trouva pour la première fois présentée à un large public européen. Un an plus tard, la revue mensuelle Europe publia un numéro spécial consacré à la poésie africaine, offrant ainsi un forum privilégié à des auteurs africains comme Dadié, Senghor ou Fodéba. Alors que dans la réception européenne, la poésie africaine, surtout celle des années quarante et cinquante, s'est très souvent trouvée associée au terme de "négritude ", la production dans le domaine de la poésie s'avère, à y regarder de plus près, d'une extrême variété et complexité.

À côté de poèmes comme celui de Senghor intitulé Femme noire, représentant tout l'inventaire iconographique de la poésie de la négritude, on trouve des recueils de poèmes comme Hosties noires - du même auteur - qui visent à présenter, à travers l'utilisation de genres traditionnels comme l'hymne ou le chant funèbre, une perspective africaine l'histoire de ce continent. Senghor opposa ainsi à l'image européenne du soldat africain brave, mais naif et puéril - largement étalée sur toutes les affiches publicitaires de la marque de cacao Banania et thématisée également, à travers l'évocation du discours paternaliste des généraux et des hommes politiques français par rapport auxquels le poème prend résolument ses distances, le souvenir de la dignité, de la fierté et du courage de ces soldats :

6 Bernard 13. Dadié, Carnet de prison, Abidjan, CEDA, 1981, p. 207.

7 V. Y. Mudimbé (éd.): "Présence Africaine and the Politics of Otherness, 1947-1987, Chicago/Londres, The University of Chicago Press, 1992. 
Vous tirailleurs sénégalais, mes frères noirs, à la main chaude sous la glace et la mort

Qui pourra vous chanter si ce n'est votre frère d'armes, votre frère de sang?

Je ne laisserai pas la parole aux ministres, et pas aux généraux Je ne laisserai pas - non! - les louanges de mépris vous enterrer furtivement

Vous n'êtes pas des pauvres aux poches vides sans honneur Mais je déchirerai les rires Banania sur les murs de France. ${ }^{8}$

À y regarder de plus près, ce poème introduisant le recueil des Hosties noires, a recours à trois registres d'écriture puisés à la fois dans la culture coloniale (pour les deux premiers) et dans les littératures orales :

1. Le registre, d'abord, du discours colonial qui se trouve indirectement ou directement cité, à travers des phrases comme "les louanges de mépris" (deuxième strophe), "la fraternité écrite sur la première page de ses monuments" ou encore la phrase "le jardin si patiemment gagné sur les épines de la brousse "( 4 e strophe);

2. Puis on trouve évoqué, en second lieu, le registre de la poésie symboliste française - Verlaine, Baudelaire - qui est indirectement citée, et immédiatement ironisé et contredit dans la troisième strophe, dans les vers suivants :

Car les poètes chantaient les fleurs artificielles des nuits cle Montparnasse

Ils chantaient la nonchalance des chalands sur les canaux de moiré et de simone

Ils chantaient le désespoir distingué des poètes tuberculeux Car les poètes chantaient les rêves des clochards sous l'élégance des ponts blancs

Car les poètes chantaient les héros, et votre rire n'était pas sérieux, votre peau noire pas classique."

8 Léopold Sédar Senghor, "Poème liminaire. A L.-G. Damas (Paris, avril 1940)". Rééd. dans Senghor, Poèmes, 1973 (coll, "Points", no 53), p. 53-54, ici p. 53 (= les cleux premières strophes du poème). Voir sur le contexte de ce poème figurant au début du cycle des Hosties noires, le volume collectif dirigé par János Riesz/ Joachim Schultz (éds.): "Tirailleurs sénégalais. zur bildlichen und literarischen Darstellung afrikanischer Soldaten im Dienste Frankreichs, Frankfurt/M., Peter Lang, 1989 (Bayreuther Beitrage zur Literaturwissenschaft vol. 13).

9 Senghor, Poème liminaire, p. 53. 
40

Senghor évoque ici, en quelque sorte et de manière très ironique, la vanité du discours poétique symboliste et des sujets qu'il traite.

3. Le troisième registre, enfin, est celui, de la poésie orale serere de l'ethnie de Senghor, qui a plus particulièrement recours à deux genres:

- celui, d'une part, du genre épidéictique qui chante les héros guerriers morts sur les champs de bataille ;

- et celui, d'autre part, de la parole adressée aux ancêtres que le poète invoque, dans l'avant-dernière strophe, à travers la figure mythique de Sira-Badral, l'ancêtre du peuple serere, évoquée dans la cinquième et avant-dernière strophe du poème:

Pardonne-moi, Sira-Bidral, pardonne-moi étoile du sud de mon sang

Pardonne à ton petit-neveu s'il a lancé sa lance pour les seize sons clu sorong.

Notre noblesse nouvelle est non de dominer notre peuple, mais d'être son rythme et son cour

Non de paitre les terres, mais comme le grain de millet de pourrir dans la terre

Non d'être la tête du peuple, mais bien sa bouche et sa trompette. ${ }^{20}$

La parole du poète-chanteur, enracinée dans la parole orale du peuple serer, redonne ainsi vie et chaleur aux corps des tirailleurs sénégalais morts, enterrés dans la glace des terres du nord, et méprisés, dans les discours politiques et poétiques, par les autres, les Européens.

Nombre de poèmes, publiés surtout dans la presse africaine, se réfèrent à des événements politiques actuels (telles les révoltes des tirailleurs sénégalais de retour de la guerre à Thiaroye en 1945), ou bien prennent pour thème les contradictions entre les promesses de liberté et les idéaux d'égalité républicains d'une part, et la réalité coloniale d'autre part. Aux côtés des Poèmes africains du poète guinéen Keïta Fodéba, publiés en 1950, la poésie de Dadié dénonce avec véhémence, à la fin des années

10 Ibid,, p. 54. Le "sorong" est un instrument de musique traditionnel des Serere, une sorte de Kora. 
quarante, ces contradictions en les replaçant dans l'horizon de sa propre expérience. Ainsi se termine, par exemple, le poème intitulé Ce que m'a donné la France (1950), rédigé par Dadié pendant son emprisonnement à Grand-Bassam, pour des "activités anti-françaises", et publié par le journal Le démocrate à Abidjan:

Elle m'a dit, la France,

Elle m'a dit par ses savants, par ses héros, par son histoire, par son génie,

Elle m'a dit avec ferveur, la France, me montrant les Bastilles qui croulent sous son regard de feu : lutte pour que ce monde-là soit ! La France ne m'a donné ni le fusil, ni la poudre, ni les balles

à jamais des frères Noirs ou Blancs, qui couchent

Mais en revanche, elle a éveillé dans mon cœur l'amour de l'humanité. ${ }^{11}$

Les lignes de démarcation tracées par la critique littéraire entre "littérature militante" et négritude s'avèrent, à y regarder de plus près, très floues et critiquables. Le roman autobiographique L'enfant noir de Camara Laye - critiqué par Mongo Beti dans un compte rendu comme "littérature à l'eau de rose" masquant les problèmes politiques - offre indirectement au lecteur l'image d'une éducation traditionnelle dont les valeurs fondamentales ont été remises en question, et en partie détruites par le colonialisme. D'autres cuvres autobiographiques, tel Climbié (1953) de Bernard Dadié, L'aventure ambiguë (1961) de Cheikh Hamidou Kane, ou encore Le baobab fou (1982) de la Sénégalaise Ken Bugul et La trabison de Marianne (1984) de Bernard Nanga reprennent le thème du conflit culturel vécu individuellement (pour lequel le roman autobiographique de Laye fournit en quelque sorte la matrice) en faisant contraster les expériences de l'école coloniale et du séjour en Europe avec les idéaux culturels et éducatifs des sociétés africaines traditionnelles. ${ }^{12}$

11 Bernard B. Dadié, "Ce que m'a donné la France", Le Démocrate. Organe quotidien du Parti Démocratique de la Côte d'Ivoire, $\mathrm{n}^{\circ} 148,2-9-1950$, p. 2; $\mathrm{n}^{\mathrm{O}} 149,23$ et 4-9-1950, p. 2.

12 Voir sur cette problématique: János Riesz, "The Conflict between European and African Civilization in West African Autobiographies", Dynamic Processes in African Societies from an Interdisciplinary Point of View. International Seminar on African Studies, 24th - 27tb July 1978. Papers and Abstracts, Bayreuth, Universität Bayreuth, 1978, p. 79-98. 


\section{De la désillusion des indépendances à l'«écriture bilingue " (1960-aujourd'hui)}

Le fossé séparant la culture française écrite et les cultures orales africaines, fossé qui a marqué les littératures africaines depuis leur naissance, a acquis, depuis les débuts de l'indépendance politique, une dimension nouvelle. Bien que la langue française soit encore, dans les anciennes colonies françaises et belges d'Afrique, langue officielle dans l'administration et dans l'enseignement, et qu'elle constitue, bien avant la langue arabe et les langues africaines, la langue écrite et littéraire dominante, se trouve néanmoins remise en question par nombre d'intellectuels africains (par exemple Sembène ou Beti) comme un reliquat de la politique coloniale culturelle d'assimilation. Depuis les années soixante-dix, on peut observer en outre, dans de nombreux États africains, l'amorce d'une politique visant à encourager systématiquement l'enseignement des langues africaines au niveau de l'enseignement primaire, et leur utilisation à la radio et à la télévision.

Cette présence renforcée des langues africaines dans les médias semi-oraux, avec la remise en question de la langue française en tant que langue officielle, a marqué durablement les littératures africaines francophones contemporaines et conduit à des formes de ré-oralisation de la littérature écrite. Dans le domaine du roman, des auteurs comme Kourouma (Les soleils des indépendances, 1968), Seydou Badian (Le sang des masques, 1976) et Amadou Hampatê Bâ (L'étrange destin de Wangrin, 1973), utilisent les genres traditionnels de la généalogie familiale et de clan ainsi que celui du "récit héroïque" pour retracer la vie de leurs protagonistes dans la société coloniale, en mettant en lumière toutes les contradictions opposant le système de valeurs traditionnel et la société coloniale créée par les Européens. Le roman de Kourouma, par exemple, décrit la déchéance psychique et physique du personnage principal, Fama, une sorte de Don Quichotte africain issu de la dynastie régnante des Doumbouya, dont les valeurs et modèles d'action traditionnels se trouvent en contradiction totale avec les nouvelles conditions politico-sociales. JeanMarie Adiaffi reprend, lui, dans La carte d'identité (1980), le schéma caractérisant le genre traditionnel de "l'histoire initiatique" et fait effectuer à son héros, le prince Agni Mélédouman, un long parcours - souvent pénible - à travers toutes les institutions importantes de la société coloniale, pour le faire accéder 
enfin à une nouvelle conscience identitaire, après s'être débarrassé des fausses identités prescrites par l'Europe. C'est sans doute Kourouma qui, parmi les auteurs de romans, pousse le plus loin l'oralisation des genres littéraires écrits. Dans ses romans Les soleils des indépendances (1968), et Monnè, outrages et défis (1990), il intègre des schémas de genres et des éléments de texte traditionnels (motifs, thèmes, proverbes, locutions), et il va jusqu'à traduire l'univers de représentations de sa propre culture - malinké - dans la matérialité (sémantique, syntaxe, morphologie) de sa propre "écriture". "La voie Kourouma", telle est la conclusion d'une étude d'Amadou Koné sur la spécificité de son écriture, "qui me semble être une réussite éclatante exige un ensemble de conditions pour donner un texte réussi. Elle exige que le romancier maitrise bien la langue de son imaginaire, sa langue maternelle et la langue européenne, la langue d'écriture " ${ }^{13}$. Dans les genres semi-oraux comme le théâtre ou la poésie, on peut observer des formes semblables de ré-oralisation: la transformation, par exemple, de chants funèbres traditionnels des Mossis dans les poèmes de Frédéric Pacéré Tintinga (Quand s'envolent les grues couronnées, 1976) ${ }^{14}$; ou encore l'utilisation d'une oralité fictive, à travers laquelle des auteurs comme Adiaffi - dans son recueil de poèmes intitulé D'éclairs et de foudres (1980) - et Bernard Zadi Zaourou dans Césarienne (1984) et Fer de lance (1975), cherchent à évoquer la situation d'un récit direct, accompagné souvent d'instruments de musique. Dans le domaine du thêâtre, le français a perdu beaucoup de son importance depuis le début des années quatre-vingt, du fait de la présence croissante des langues africaines dans les médias audiovisuels, et de la diffusion croissante des pièces à la radio et à la télévision. Certains groupes de thêâtre, comme le Théâtre Rituel de Werewere Liking ou le Théâtre Kotéba de Souleymane Koly, qui jouent essentiellement dans les banlieues et sur les marchés, tentent de combler le fossé séparant la culture française écrite et

13 Amadou Koné, "Bilinguisme et écriture du français : écrire deux langues à la fois ", Le français aujourd hui, une langue à comprendre. Mélanges offerts à Jürgen Olbert, Gilles Dorion, Franz-Joseph Meißner, János Riesz et Ulf Wielandt (dir.), Frankfurt/M., Diesterweg, 1992, p. 440-448, ici p. 448.

14 Voir Claudia Ortner-Buchberger, Frankophone afrikanische Lyrik nach der Unabhängigkeit. Kontext und Intertext. Lyrik in der Elfenbeinküste und Burkina Faso (1970-1985), Frankfurt/M., Verlag für Interkulturelle Kommunikation, 1993 (Studien zu den frankopbonen Literaturen außserhalb Europas vol. 5). 
44

les cultures africaines orales par le recours à des formes d'écriture et de mise en scène syncrétiques. Liking choisit d'utiliser la forme du rituel religieux traditionnel, dans lequel la danse et les masques occupent une place centrale, alors que Koly et sa troupe reprennent dans leurs pièces la tradition des chants et récits Kotébas, ethnie du nord de la Côte d'Ivoire, en utilisant dans les dialogues le "français d'Abidjan", fortement imprégné d'éléments africains. La tendance, qui se fait également jour ici, "d'écrire la littérature en deux langues à la fois ", tendance que l'écrivain ivoirien Amadou Koné considère comme la caractéristique principale des littératures africaines contemporaines, met la critique littéraire devant un nouveau défi : celui de réajuster sa grille de concepts et de lecture, pour l'adapter à la complexité culturelle des littératures africaines et à leur réseau de discours tissé d'éléments à la fois oraux et écrits.

Le roman Le devoir de violence de Yambo Ouologuem, publié en 1968 recouvre à la fois la problématique des textes littéraires nés dans le sillage des indépendances africaines, et celle d'une écriture que l'on pourrait appeler "semi-orale". Il est en même temps un des romans les plus fascinants de la littérature africaine écrite, qui reçut en 1968 le prestigieux prix littéraire Renaudot. Ce roman est à la croisée de plusieurs tendances évoquées, à la fois sous l'angle diachronique et sous l'angle synchronique: à savoir la réception, intense et multiple, des littératures européennes, et plus généralement occidentales; et l'intégration, à travers le style, la sémantique et les références intertextuelles, des littératures africaines orales ${ }^{15}$.

Comme d'autres œuvres africaines des années soixante et soixante-dix, telles celles d'Amadou Kourouma dans le domaine francophone ou celles d'Ayi Kwei Armah dans le domaine anglophone, ce roman est à la fois anti-colonialiste et très critique envers les détenteurs du pouvoir dans les pays africains indépendants. Il raconte, en effet, l'histoire du royaume du Mali sous la dynastie (imaginaire) des Saif, depuis la conquête de l'Afrique de l'Ouest par l'islam au XIII siècle jusqu'à l'époque postcoloniale des indépendances. La vision que donne Ouologuem de cette

15 Voir sur ce point : Bernard Mouralis, "Un carrefour d'écritures: "Le devoir de violence "de Yambo Ouologuem ", Rechercbes et travaux (Université de Grenoble), bulletin, $\mathrm{n}^{\circ} 27,1984, \mathrm{n}^{\circ}$ thématique "Littératures africaines d'écriture française ", p. 75-92. 
histoire de longue durée, s'étalant sur 700 ans est foncièrement pessimiste. Elle montre une histoire marquée par la violence, la domination oppressive du petit peuple par les gens au pouvoir et l'esclavage où les formes extérieures changent, mais non pas les structures économiques, sociales et politiques de base. La colonisation européenne apparaît, dans cette perspective, comme une constellation parmi d'autres à laquelle les détenteurs traditionnels du pouvoir, symbolisés/incarnés par la dynastie des Saif, ont pu s'adapter à merveille - contrairement au petit peuple. Le colonisateur européen (ici le Français) est vu, sous cet angle, à la fois comme manipulateur et comme manipulé, comme conquérant victorieux et comme conquérant malmené à son insu par les ruses des castes dominantes indigènes.

En même temps, et comme nombre d'autres textes littéraires africains, Le devoir de violence constitue un carrefour d'écritures, un tissu intertextuel extrêmement complexe et riche: il utilise le genre européen du roman, à travers différents genres (roman historique, roman d'aventures, roman pornographique, roman de formation); mais aussi l'épopée dont le souffle est présent à travers les toutes premières paroles du narrateur qui invoquent la gloire de Dieu, en arabe, et se proposent de retracer la gloire d'un des grands empires de l'histoire africaine:

Nos yeux boivent l'éclat du soleil, et, vaincus, s'étonnent de pleurer, Mascbllab! oua bismillab!... Un récit de l'aventure sanglante de la négraille - honte aux hommes de rien! - tiendrait aisément dans la première moitié de ce siècle; mais la véritable histoire des Nègres commence beaucoup, beaucoup, plus tôt, avec les Saifs, en l'an 1202 de notre ère, dans l'Empire africain de Nakem, au sud de Fezzan, bien après les conquêtes d'Okba ben Nafi el Fitri.

Raconter la splendeur de cet empire - dont la renommée, atteignant le Maroc, le Soudan, l'Égypte, l'Abyssinie, la noble et sainte ville de la Mecque, fut connue des Anglais, des Hollandais, des Français, des Espagnols, des Italiens, et, bien entendu, des Portugais - n'offrirait rien que du menu folklore. ${ }^{16}$

Le devoir de violence constitue aussi un exemple particulièrement frappant de ce qu'on pourrait appeler le "contre-discours", caractéristique pour la littérature africaine écrite depuis les années quarante: renversant le modèle imaginatif (de l'idéologie colo-

16 Yambo Ouologuem, Le devoir de violence, Roman, Paris, Seuil, 1968, p. 9. 
46

niale) qui l'a marquée à ses débuts, la littérature africaine incarne, dans ses ouvres majeures, en effet, différents types de contre-discours subversifs ${ }^{17}$, de discours "à rebrousse-poil", une position que Ashcroft et ses co-auteurs ont appelée, dans leur livre manifestaire paru en 1989, The Empire Writes Back ${ }^{18}$. Le livre de Ouologuem va, en effet, beaucoup plus loin que les représentants de la génération précédente d'écrivains et d'intellectuels comme Senghor pour qui la culture orale traditionnelle de son peuple, les Serere, avait encore fourni un cadre d'identification majeur. Ouologuem allait à l'encontre - et résolument à contre-courant - de tous les modèles d'identification existants en Afrique, coloniaux, précoloniaux et postcoloniaux, en montrant leur envers, et en les déconstruisant. Avec cette œuvre démystificatrice et foncièrement critique, ayant émergé en même temps que celles de Kourouma ${ }^{19}$, de Wole Soyinka, de Jean-Marie Adiaffi et d'Ayi Kwei Armah, qui poursuivent foncièrement la même orientation, la littérature africaine a fini par trouver sa propre postmodernité 20 .

\section{Conséquences pour l'enseignement des littératures africaines francophones}

Les réflexions présentées ci-dessus incitent à plusieurs conclusions, en ce qui concerne les perspectives en matière d'enseignement des littératures francophones, et des littératures africaines d'écriture française en particulier:

17 Voir sur ce point Hans-Jürgen Lüsebrink, "De l'incontournabilité de la fiction dans la connaissance historique. Questionnements théoriques à partir de romans historiques contemporains d'Alejo Carpentier, de Yambo Ouologuem et d'Ousmane Sembène ", Neobelicon, vol. XVI/2, Budapest, 1989, p. 107128 ; et Aliko Songolo, "Fiction et subversion: "Le Devoir de violence" "Prêsence africaine, $\mathrm{n}^{\mathrm{O}} 120,4^{\mathrm{e}}$ trimestre 1981 , p. 17-34.

18 Bill Ashcroft/ Gareth Griffiths/ Helen Tiffin, The Empire Writes Back. Theory and Practice in Post-Colonial Literatures, London/ New York, Routledge, 1989.

19 Voir la mise en rapport des cuvres de Ouologuem et de Kourouma par Anita Kern, "On "Les soleils des indépendances" and "Le devoir de violence" ", Présence africaine, $\mathrm{n}^{\circ} 85,1^{\text {er }}$ juin 1973, p. 209-230.

20 Voir sur la spécificité de la littérature africaine postmoderne: János Riesz, "Afrikanische Literatur im Zeichen der Postmoderne", dans Riesz, Koloniale Mytben - afrikaniscbe Antworten : Europäisch-afrikanische Literaturbeziehungen I, Frankfurt/M., Verlag für Interkulturelle Kommunikation, 1993 (Studien $z u$ den frankophonen Literaturen außerbalb Europas vol. 1), p. 3-24. 
1. Face à la recherche en littérature africaine longtemps dominée par des questionnements thématiques et idéologiques, au sens étroit des termes, il paraît nécessaire de mettre nettement plus l'accent sur les aspects formels, esthétiques, culturels et linguistiques des textes littéraires africains : c'est-à-dire leur matérialité ${ }^{21}$ indissociablement liée aux représentations idéologiques et aux prises de position politiques qu'ils énoncent.

2. La prise en considération d'un ancrage culturel fondamentalement multiple, marqué par les cultures orales (précoloniales et souvent très vivantes jusqu'à présent) et la culture coloniale, ses modèles d'écriture et ses formes d'acculturation, incite à la fois à un décloisonnement interdisciplinaire des recherches en littératures africaines et à une plus forte spécialisation. Enseigner des textes comme ceux, précédemment cités et analysés, de Senghor et de Ouologuem présuppose l'intégration de travaux littéraires, mais aussi ethnologiques, linguistiques, historiques, voire de spécialistes islamisants (les chroniques des Fetach qui constituent une des sources essentielles de l'écriture intertextuelle de Ouologuem). Un tel travail interdisciplinaire peut se mener, sur le plan institutionnel, soit dans des groupes de recherche ou dans des centres d'études africaines, comme celui de l'Université de Bayreuth en Allemagne fondé au début des années quatre-vingt.

3. L'orientation de plus en forte, depuis les années soixante, de l'écriture littéraire africaine vers les littératures et cultures orales, et la vision de vouloir écrire dans "deux langues à la fois" (A. Koné ${ }^{22}$ ), présuppose, par contre, des connaissances approfondies d'une ou de plusieurs langues et cultures africaines. Une valorisation, et en même temps un fort encouragement, des travaux de chercheurs sur le continent africain dans ce domaine paraît indispensable. Cela devrait conduire à une beaucoup plus forte coopération entre chercheurs africains et occidentaux et à la création de chaires, très rares encore, de littératures et cultures Karl Ludwig Pfeiffer, Materialität der Kommunikation, Frankfurt/M., Suhrkamp, 1988. 
africaines orales, domaines généralement couverts, de manière souvent insatisfaisante, par l'ethnologie ou l'anthropologie.

4. L'autre versant de l'ancrage interculturel des littératures africaines, l'héritage colonial et postcolonial, longtemps négligé à cause de l'idéologie de la rupture qui a imprégné les années de conquête des indépendances, a suscité une attention croissante auprès des chercheurs, notamment en France et en Allemagne, ces dernières années. La prise en considération de ce champ d'investigation, dans la recherche et l'enseignement, ne nécessite pas seulement des travaux, trop négligés par les littéraires, sur la presse et les institutions socioculturelles encadrant les littératures africaines tant en Afrique que sur d'autres continents, mais aussi des concepts et des instruments d'analyse propres à penser les rapports interculturels constitutifs pour les littératures africaines écrites. Questionner l'apport possible de théories littêraires et culturelles comme la théorie de la réception, la sémiotique, la théorie des genres ou l'analyse des transferts culturels pour l'étude des littératures africaines est une tâche largement entamée, par de nombreux chercheurs; mais il faudrait peut-être aussi essayer de penser, et de cerner avec acuité, les limites de ces instruments théoriques tous forgés en Occident, et élaborés pour l'essentiel à partir de textes littéraires écrits en langues européennes marquées par une longue tradition scripturale et livresque, pour l'analyse adéquate de ces écritures fondamentalement interculturelles, à cheval sur l'oral et l'écrit, et imprégnées de strates culturelles multiples, que sont les littératures africaines dites "francophones" 23 .

23 Voir à ce sujet les réflexions dans Literary Theory and African Literature' Théorie littéraire et littérature africaine, Josef Gugler, Hans-Jürgen Lüsebrink et Jürgen Martini (dir), Münster/Hamburg, LIT-Verlag, 1994 (Beiträge zur Afrikaforschung, vol. 3) (en particulier la contribution de Biodun Jeyifo sur "African Literature and Theories of Decolonization", p. 17-30; et notre postface intitulée "Questionnements et mises en perspectives", p. 163-172). 